\title{
Pengelolaan sampah anorganik pada Alila Villas Uluwatu, Bali
}

\author{
Inorganic waste management at Alila Villas Uluwatu, Bali
}

\author{
Sulfa Ilmiyah $^{1 *}$, A.A.G. Raka Dalem ${ }^{1,2}$, dan I Ketut Muksin ${ }^{1}$ \\ ${ }^{1)}$ Program Studi Biologi, Fakultas Matematika dan Ilmu Pengetahuan Alam, Universitas Udayana, Bali, Indonesia - 80361 \\ ${ }^{2)}$ Pusat Unggulan Pariwisata, Universitas Udayana, Bali, Indonesia - 80361
}

*Email: ilmiyahsulfa4@gmail.com

Diterima 3 Mei $2021 \quad$ Disetujui 23 Juni 2021

\section{INTISARI}

Permasalahan lingkungan merupakan hal kompleks yang sangat berpengaruh terhadap semua komponen di dalam ekosistem. Masalah lingkungan salah satunya dapat diakibatkan oleh produksi sampah yang tidak dikelola dengan baik, misalnya pada industri perhotelan. Kegiatan perhotelan merupakan salah satu kegiatan yang menghasilkan berbagai macam sampah, baik yang mudah terurai atau tidak maupun yang beracun atau tidak. Produk yang tidak mudah terurai dan beracun dapat mencemari lingkungan apabila tidak ditangani dengan baik. Alila Villas Uluwatu (AVU) merupakan salah satu hotel di Bali yang berkomitmen untuk menerapkan prinsip pariwisata ramah lingkungan dan upaya dalam menjaga lingkungan dengan menerapkan usaha meminimalisasi produksi sampahnya. Tujuan penelitian ini adalah untuk mengetahui strategi AVU di dalam menjaga lingkungan, khususnya dalam menangani sampah anorganik yang dihasilkan, seperti kaca, kertas dan plastik. Metode yang digunakan dalam penelitian ini adalah wawancara dan observasi langsung di lapangan serta pemeriksaan dokumen. Analisis data dilakukan secara deskriptif kualitatif dan kuantitatif. Hasil penelitian menunjukkan bahwa strategi pengelolaan sampah pada AVU meliputi usaha untuk meminimalisasi produksinya salah satu caranya dengan mendaur ulang sampah anorganik yang tersedia serta dengan menggunakan bahan yang lebih ramah lingkungan seperti sikat gigi dengan pegangan yang terbuat dari kayu, sedotan kertas serta sedotan bambu.

Kata kunci: Alila Villas Uluwatu, masalah lingkungan, pariwisata berkelanjutan, sampah

\begin{abstract}
Environmental problems are complex things that they are very influential on all components in the ecosystem. One of the environmental problems is caused by the production of waste that is not treated properly, for example in the hotel industry. Tourism is one of the activities that produce various kinds of waste, both environmentally friendly and not. Products that are not environmentally friendly can pollute the environment if they do not handled properly. Alila Villas Uluwatu (AVU) is one of hotels in Bali that are committed to environmentally friendly and efforts to protect the environment by minimizing waste production. The objective of this research was to find out AVU's strategies in protecting the environment, especially in handling the resulting inorganic waste, such as glass, paper and plasctics. The method utilized in data collection on this study was through conducting interview, direct observation in the field and examination of related documents. Data analysis was performed descriptively, either in qualitative and quantitative forms. The results showed that the waste management strategy in AVU included efforts to minimize inorganic waste production and by using more environmentally friendly materials such as toothbrushes with wooden handles, paper straws and bamboo straws.
\end{abstract}


Keywords: Alila Villas Uluwatu, environmental problems, sustainable tourism, waste

\section{PENDAHULUAN}

Isu lingkungan menjadi penting dalam perkembangan dunia. Upaya pemantauan dan pengelolaan lingkungan dapat terjadi pada seluruh sektor, khususnya sektor pariwisata, salah satunya yaitu perhotelan (Wahyuningsih, 2020). Permasalahan yang menyangkut lingkungan sangat riskan bagi kebutuhan manusia, baik dari segi jasa ataupun barang (Bagiastra \& Damayanti, 2019). Tidak dapat dipungkiri lagi bahwa telah terjadi kerusakan lingkungan disebabkan oleh aktivitas manusia, terlebih lagi pada bidang industri. Industri perhotelan yang berkomitmen terhadap ramah lingkungan akan sangaat penting artinya dalam mewujudkan pembangunan berkelanjutan, sehingga dibutuhkan investigasi ilmiah yang bertujuan untuk menganalisis praktik pengelolahan hotel yang ramah lingkungan yang disebut green hotel (Kementerian Pariwisata Republik Indonesia, 2016).

Pelaksanaan kegiatan industri akan merusak lingkungan apabila tidak memiliki visi ke arah sustainable development dan tidak menerapkan sistem manajemen lingkungan dengan maksimal. Tidak banyak hotel di Indonesia yang memiliki komitmen terhadap prinsip ramah lingkungan. Sedikitnya pemahaman terhadap hotel ramah lingkungan (green hotel) yaitu hotel yang memiliki konsep untuk mempraktikkan kesadaran untuk menjaga kualitas lingkungan dapat berakibat buruk terhadap lingkungan atau jalannya pembangunan keberkelanjutan. Pandangan wisatawan terhadap green hotel memiliki hubungan yang kuat dengan nilai lingkungan (Teng et al., 2018).

Green hotel juga dapat menjadi pedoman bersaingnya hotel dalam industri pariwisata seASEAN guna membantu hotel menerapkan pariwisata berwawasan lingkungan. Hal tersebut mengarah pada wisatawan yang dituntut selektif dalam memilih akomodasi yang ramah lingkungan (Kementerian Pariwisata Republik Indonesia, 2016). Menurut Brian (2019), green hotel juga didefinisikan sebagai hotel dengan pelestarian energi yang jelas serta memberikan dampak positif terhadap lingkungan.

Seiring dengan berkembangnya destinasi wisata, maka jumlah pencemaran yang dihasilkan akan berbanding lurus dengan jumlah wisatawan yang datang. Dengan demikian, dapat dikhawatirkan apabila banyak wisatawan yang berkunjung, akan berpotensi meningkatkan pencemaran yang terjadi terhadap lingkungan. Menyadari hal tersebut, maka saat ini mulai berkembang sebuah penerapan operasional pada hotel demi mewujudkan pembangunan yang berkelanjutan, yang dikenal sebagai hotel berwawasan lingkungan atau eco-friendly hotel (Webster, 2006).

Hotel dapat dikatakan ramah lingkungan apabila hotel tersebut mensinergikan operasional sehari-harinya dengan upaya mengurangi dampak negatif terhadap lingkungan melalui penyusunan sistem efisiensi energi, program daur ulang, pemanfaatan energi terbarukan, sistem pengairan, penggunaan produk organik pada makanan dan program yang bertujuan mereduksi penggunaan air (Ruiz et al., 2010). Selain itu, keberhasilan operasional hotel berwawasan lingkungan juga tergantung pada faktor pendorongnya, seperti yang diungkapkan oleh Shairullizan et al. (2013) bahwa faktor pendorong (driver factors) tersebut meliputi government, customer demand, level of competition, greenness at the organizational level, dan attitude toward change.

Nyatanya yang terjadi tahun 2020, pengelolaan sampah masih menjadi tanggung jawab pemerintah, sedangkan Undang-undang No.18 Tahun 2008 yang mengatur tentang Pengelolaan Sampah, pengelolaan sampah menjadi tanggung jawab bersama (Puteri, 2017). Hampir semua hotel yang ada di Bali telah memilah sampahnya sebelum dibuang ke Area Pembuangan Akhir (Dalem et al., 2010).

Alila Villas Uluwatu merupakan salah satu hotel bintang di Bali yang bersinergi dalam 
menerapkan penggunaan bahan ramah lingkungan dan meminimalisir produksi sampah. Sampah diminimalisir penggunaannya dengan cara didaur ulang dan digantikan dengan bahan lain yang mempunyai fungsi sama tetapi lebih ramah lingkungan.

Tujuan penelitian ini adalah untuk mengetahui usaha-usaha AVU di dalam meminimalisasi produksi sampah anorganik seperti kaca, kertas dan plastik serta menggunakan bahan-bahan ramah lingkungan agar sampahnya lebih mudah terurai secara alami (biodegradable).

\section{MATERI DAN METODE}

\section{Tempat dan waktu penelitian}

Penelitian ini dilakukan di Alila Villas Uluwatu, Bali (S 850'45”, E 115 08'13”) pada tanggal 6 - 30 Januari 2020. Alila Villas Uluwatu memiliki ketinggian tempat 100 meter di atas permukaan laut dengan luas area sebesar 60.000 $\mathrm{m}^{2}$ (Gambar 1) (Alila Hotels and Resorts, 2020).

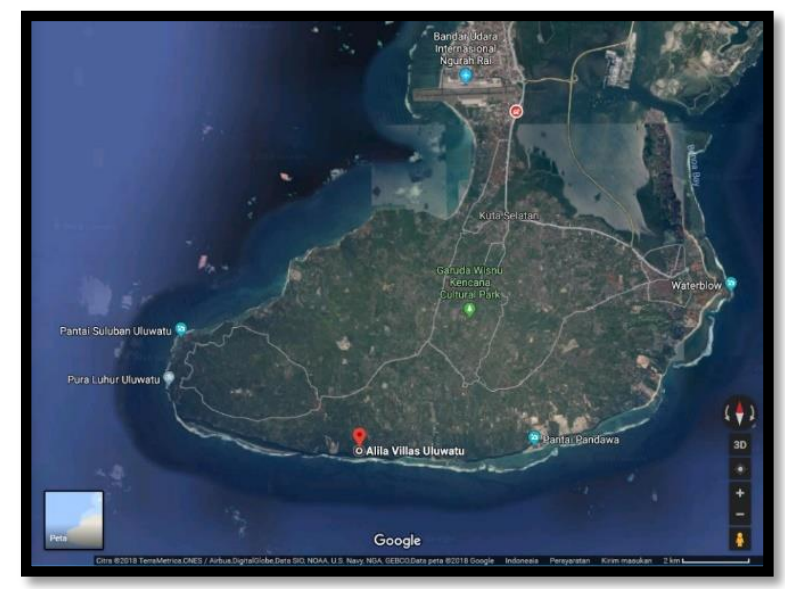

Gambar 1. Lokasi Alila Villas Uluwatu (Alila Hotels and Resorts, 2020)

\section{Bahan dan alat}

Alat-alat yang digunakan dalam penelitian ini diantaranya alat tulis berupa buku, bolpoin, ponsel genggam (handphone) untuk merekam hasil wawancara serta kamera untuk mendokumentasikan kegiatan penelitian.

\section{Metode}

Metode yang digunakan dalam penelitian ini diantaranya metode observasi yaitu turun langsung untuk meneliti objek penelitian (Hasanah, 2017), studi literatur atau kepustakaan dimana dilakukan kajian pustaka terhadap sumber-sumber yang relevan sehingga dapat menunjang penelitian, pemeriksaan dokumen yang didapat dari lokasi penelitian, dan wawancara langsung dengan Environment and General Affair Manager Alila Villas Uluwatu, yaitu Bapak I Ketut Muliarta dan beberapa pegawai atau staf pemilahan sampah anorganik. Hal-hal yang spesifik lainnya dapat memberi wawasan baru bagi hotel-hotel lain yang ingin menuju green hotel namun masih terbatas informasinya. Data yang telah diperoleh tersebut selanjutnya dilakukan analisis data secara kualitatif dan kuantitatif.

\section{Analisis data}

Teknik analisis data dalam penelitian ini yaitu secara kualitatif dan secara kuantitatif. Penelitian kualitatif sendiri bertujuan untuk memperoleh gambaran seutuhnya mengenai suatu hal menurut pandangan manusia terkait objek yang diteliti. Penelitian kualitatif ini berhubungan dengan ide, persepsi, pendapat, atau kepercayaan orang yang meneliti dan secara keseluruhan tidak dapat diukur dengan angka (Basuki, 2006). Selain menggunakan data kualitatif, juga menggunakan data kuantitatif. Data kuantitatif diolah menggunakan program Microsoft Excel 2010.

\section{HASIL}

Jenis sampah yang menjadi bahasan pada penelitian ini diantaranya berupa kertas, kaca dan plastik yang digunakan di lokasi AVU. Produksi tiga jenis sampah pada Alila Villas Uluwatu ditunjukkan pada Tabel 1. Data ini merupakan data terbaru yang dikeluarkan oleh AVU sebagai bahan evaluasi untuk tahun berikutnya. Produksi sampah pada tahun 2018 meliputi sampah kaca, kertas dan plastik, adapun besarannya yaitu pada sampah berbahan kaca produksi sampahnya sebesar 7299,55 kg, jenis sampah berbahan kertas sebesar 7569,5 kg, sedangkan untuk jenis sampah 
berbahan plastik yaitu 4200,92 kg. Angka ini jauh lebih sedikit jika dibandingkan dengan produksi bahan jenis kertas dan kaca.

Tabel 1. Produksi Tiga Jenis Sampah pada Alila Villas Uluwatu tahun 2018

\begin{tabular}{cc}
\hline Bahan & Tahun 2018 (kg) \\
\hline Kaca & 7299,44 \\
Kertas & 7569,5 \\
Plastik & 4200,92 \\
\hline
\end{tabular}

Produksi sampah pada Alila Villas Uluwatu Bali sejak tahun 2018 ditampilkan pada diagram (Gambar 1), diantaranya berupa kaca, kertas dan plastik.

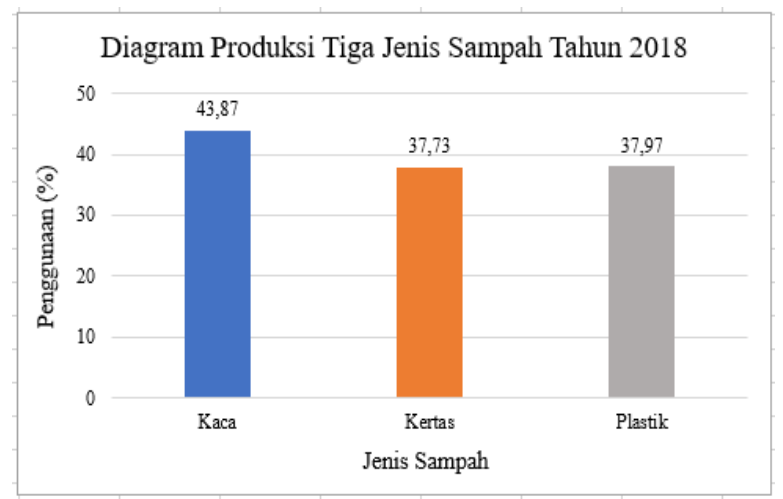

Gambar 2. Diagram Produksi Tiga Jenis Sampah Tahun 2018

Tahun 2018 terdapat 47.396 guest night dengan penggunaan produksi sampah sebesar $0,4024 \mathrm{~kg}$ per guest night (Gambar 3).

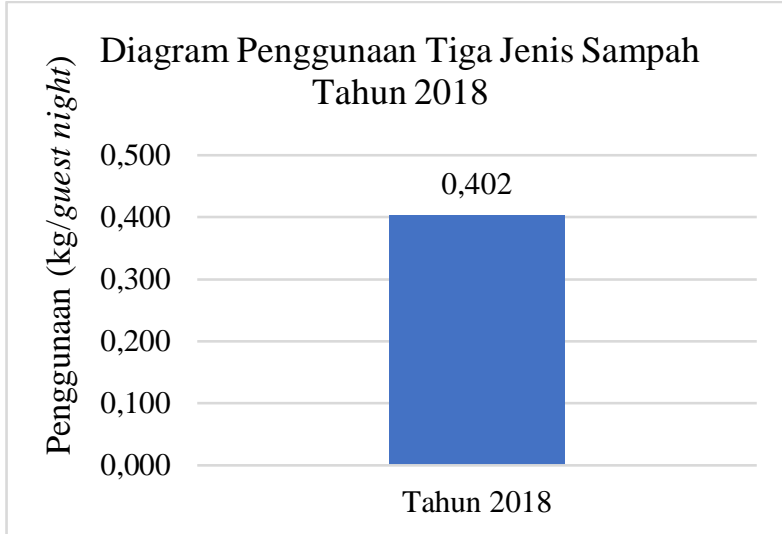

Gambar 3. Diagram Produksi Tiga Jenis Sampah per Guest night 2018

Pada tahun 2018, persentase sampah kaca yang diproduksi oleh AVU adalah sebanyak 43,87\%. Jumlah tersebut berbanding lurus dengan jumlah yang digunakan untuk didaur ulang dengan tidak adanya sisa dari proses daur ulang tersebut (Gambar 4). Tidak ada sisa kaca yang tidak dipergunakan pada tahun 2018, hal ini dikarenakan pihak hotel sudah mempunyai prosedur terukur yang khusus guna memperhatikan betul pemanfaatan dari penggunaan kaca yang tersedia di AVU.

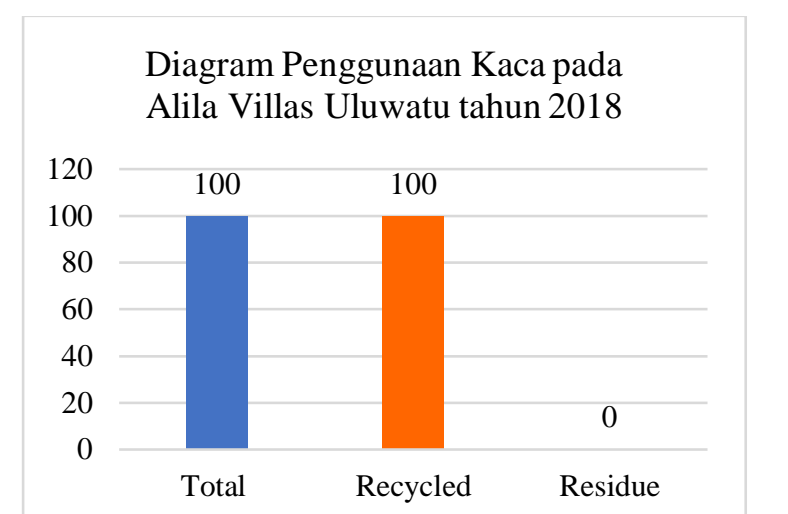

Gambar 4. Diagram Produksi Sampah Kaca pada AVU tahun 2018

Menurut perhitungan ukuran aktivitas (activity measure), didapatkan pada tahun 2018 sebanyak $0,154 \mathrm{~kg}$ per guest night. Penggunaan kaca yang dipakai pada AVU cenderung stabil dengan jumlah guest night (Gambar 8).

Tahun 2018 merupakan tahun dimana kertas yang didaur ulang lebih banyak daripada sisanya, yaitu sebanyak $96,50 \%$ dengan sisa 3,52\% seperti yang ada pada Gambar 5. Penggunaan kertas pada tahun 2018 dengan ukuran aktivitas (activity measure) telah diperoleh sebanyak $0,157 \mathrm{~kg}$ per guest night (Gambar 7).

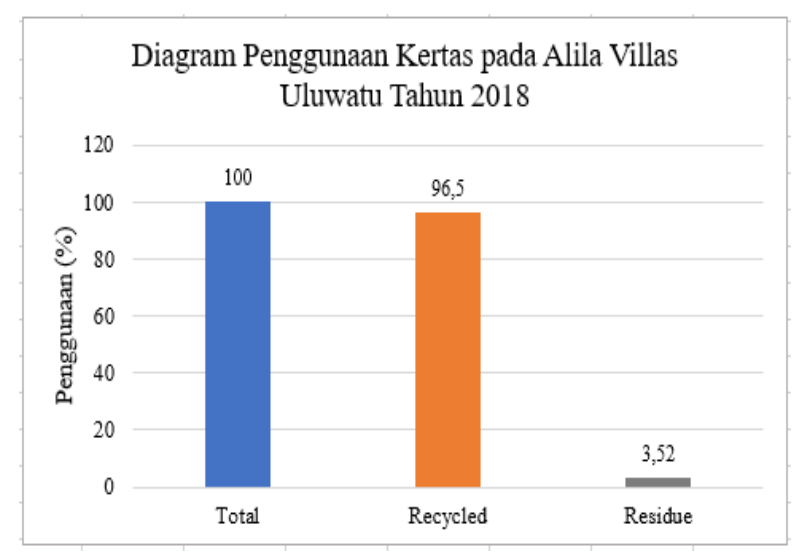

Gambar 5. Diagram Produksi Sampah Kertas dan Recycle nya Tahun 2018 
Terdapat dua jenis kertas yang digunakan di AVU yaitu kertas ecolabelled dan non ecolabelled (Gambar 6).

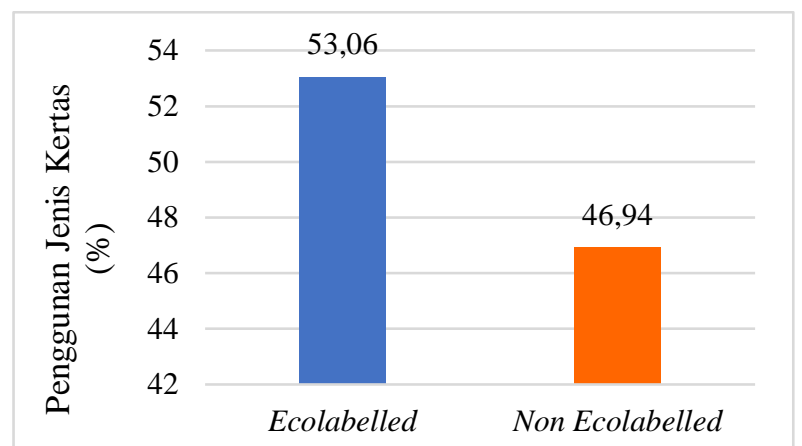

Gambar 6. Diagram Jenis Kertas Ecolabbeled dan Non Ecolabelled AVU Tahun 2018

Data diagram terkait produksi sampah plastik dan recycle nya pada tahun 2018 dapat direpresentasikan bahwa total jumlah plastik yang digunakan berbanding lurus dengan jumlah plastik yang didaur ulang (Gambar 7).

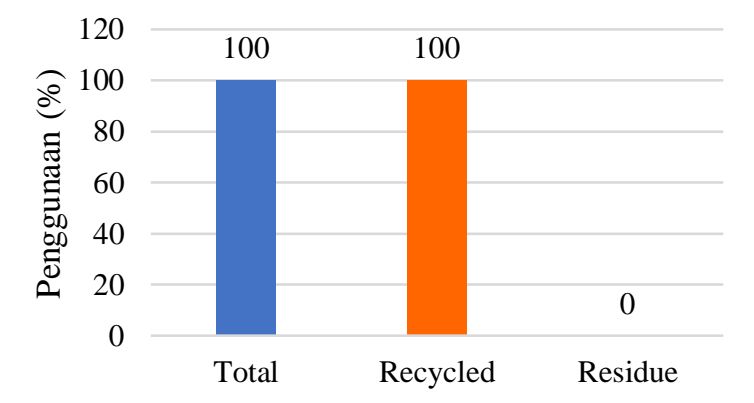

Gambar 7. Diagram Produksi Sampah Plastik Tahun 2018

Berdasarkan hasil perhitungan dengan membagi penggunaan plastik dengan activity measure (guest night) dapat dilihat bahwa penggunaan plastik pada tahun 2018 sebanyak $0,088 \mathrm{~kg}$ per guest night dengan 47.396 guest night (Gambar 8).

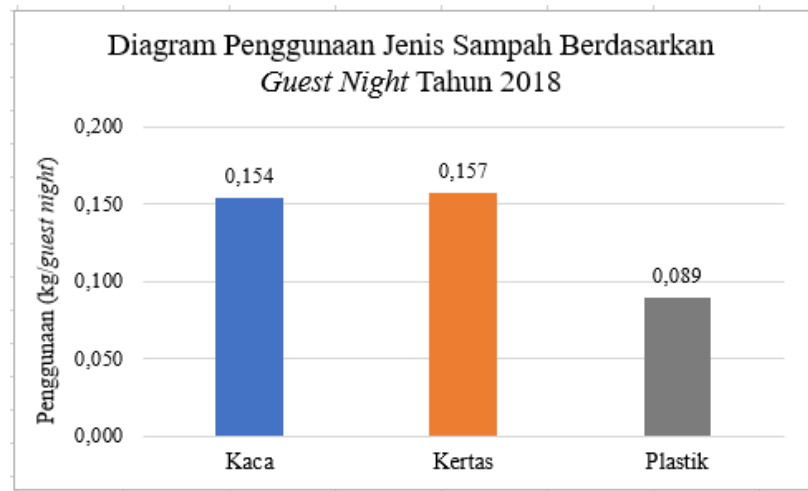

Gambar 8. Diagram Penggunaan Jenis Sampah Berdasarkan Guest Night Tahun 2018

\section{PEMBAHASAN}

\section{Produksi Sampah dan Strategi Minimalisasinya}

Produksi sampah pada Alila Villas Uluwatu Bali sejak tahun 2018 ditampikan pada diagram (Gambar 2), diantaranya berupa kertas, kaca dan plastik. Berdasarkan diagram di atas yang sudah disajikan dalam bentuk persentase, perbedaan jumlah penggunaan ketiga jenis sampah tersebut digunakan dalam hal yang berbeda-beda. Kertas pada Alila Villas Uluwatu digunakan sebagai bahan urusan perkantoran, seperti koran, majalah, kardus ataupun tisu. Penggunaan kaca digunakan untuk botol air minum kaca dan kaca panel. Sedangkan plastik menggunakan jenis PolyEthylene Terephthalate (PET) yang bernomorkan 1. Strategi Alila Villas Uluwatu dalam meminimalisasi produksi sampah adalah dengan menggunakan bahan-bahan yang lebih ramah lingkungan.

Penggunaan dari ketiga bahan tersebut sesuai dengan jumlah guest night yang berkunjung pada Alila Villas Uluwatu. Menurut data yang sudah didapat, terdapat empat bidang yang perlu diperhitungkan, diantaranya guest staying overnight (tamu yang menginap), staff AVU yang menginap karena satu dan lain hal, day guest (tamu yang berkunjung ke hotel tidak untuk menginap, seperti untuk event dan wedding, melakukan spa, bermain golf, fitness ataupun urusan bisnis) ataupun pengunjung yang sekadar makan siang atau makan malam di restaurant Alila Villas Uluwatu, yaitu The Warung \& Cire. Perhitungan dari total guest night ini dihitung per orang per hari dari yang berkunjung ke AVU. Misalnya, dua orang tamu menginap selama tiga malam, sama dengan enam guest nights.

Hasil wawancara dengan Bapak Muliarta selaku Environment and General Affair Manager didapatkan data bahwa total overnight guest dihitung per orang dengan lamanya orang tersebut menginap. Data day visitor menunjukkan tamu yang tidak menginap, pemakaian kamar atau kunjungan kurang dari 24 jam. Day visitor itu bisa berupa kunjungan untuk event dan wedding 
ataupun hanya merehatkan badan dengan menikmati fasilitas spa. Non-resident Restaurant Covers menunjukkan angka tamu yang berkunjung ke restaurant dan tidak untuk menginap. Perhitungan dari total guest night per tahun ditentukan dengan penjumlahan dari (total guest staying overnight $)+($ staff night $)+($ total day guest : 3$)+($ total non-resident restaurant cover: 4). Data guest night AVU pada tahun 2018 terdapat 47.396 guest night. Sehingga dengan membagi produksi sampah kertas, kaca dan plastik dengan guest night pada tahun yang sama maka dapat dilihat hasilnya pada tahun 2018 yaitu sebanyak 0,4024 kg guest night seperti pada diagram (Gambar 3).

\section{Produksi Sampah Kaca dan Strategi Minimalisasinya}

Kaca merupakan bahan yang memiliki sifat fisik yang tembus pandang cahaya dan memiliki daya guna yang baik walaupun sudah menjadi limbah. Kaca ini didapatkan dari berbagai proses, yaitu proses biologi, kimia dan fisika yang hasilnya berupa padatan (Alfionita \& Rahardian, 2019). Kaca mempunyai peran bagi lingkungan sekitar, baik positif maupun negatif.

Aspek yang bisa dilihat dari kaca yaitu menunjang kebutuhan masyarakat dan kebutuhan dunia industri, khususnya di perhotelan yang mana banyak sekali membutuhkan kaca yang dipergunakan dalam berbagai bentuk. Aspek negatif dari sampah kaca yaitu jika limbah kaca tidak ditangani dengan serius maka jenis sampah ini akan berdampak buruk bagi lingkungan, serta bisa melukai manusia. Limbah kaca dapat berdampak positif terhadap lingkungan apabila didaur ulang dengan cara yang benar, yang nantinya akan menjadi produk baru, seperti botol kaca, gelas kaca, piring kaca dan lain sebagainya (Noel, 1998).

Alila Villas Uluwatu merupakan industri perhotelan yang sangat memperhatikan limbah kaca, kaca pada hotel ini dimanfaatkan untuk membuat berbagai macam produk, seperti botol kaca bening, botol kaca berwarna, gelas kaca dan kaca bentuk lainnya. Kaca yang dipakai di AVU merupakan kaca dari suplier dan nantinya sampahnya akan dikirim ke Tambyak Lestari. Tambyak Lestari merupakan perusahaan lokal yang bekerja sama dengan AVU untuk mengambil sampah. Sampah-sampah ini dipilah berdasarkan beberapa kategori, diantaranya digunakan kembali, didaur ulang dan dikirim ke pembuangan akhir (TPA) milik pemerintah (PT. Bukit Uluwatu Villa Tbk., 2020). Berdasarkan data yang diperoleh dari AVU, produksi sampah kaca pada Alila Villas Uluwatu pada tahun 2018 (Gambar 3) cenderung stabil. Pada tahun 2018, persentase sampah kaca yang diproduksi oleh AVU adalah sebanyak 43,87\%. Jumlah tersebut berbanding lurus dengan jumlah yang digunakan untuk didaur ulang dengan tidak adanya sisa dari proses daur ulang tersebut. Tidak ada sisa kaca yang tidak dipergunakan pada tahun 2018, hal ini dikarenakan pihak hotel sudah mempunyai prosedur terukur yang khusus guna memperhatikan betul pemanfaatan dari penggunaan kaca yang tersedia di AVU.

\section{Produksi Sampah Kertas dan Strategi Minimalisasinya}

Kertas merupakan lembaran yang terdiri dari serat-serat selulosa yang saling jalin-menjalin dan dihasilkan dari kompresi serat dari pulp (Departemen Perindustrian, 1982). Alila Villas Uluwatu memanfaatkan kertas untuk berbagai hal. Kertas pada AVU, dominan penggunaannnya untuk kebutuhan perkantoran dan administrasi.

Penggunaan kertas pada AVU yaitu untuk dijadikan koran, tisu, kertas sebagai alat cetak di kantor, cardboard, box ataupun lunch box. Sampah kertas yang sudah tidak digunakan lagi dikirim ke Tambyak Lestari. Tahun 2018 merupakan tahun dimana kertas yang didaur ulang lebih banyak daripada sisanya, yaitu sebanyak $96,50 \%$ dengan sisa $3,52 \%$. Sisa sampah kertas yang ada, tidak serta merta dibuang ke alam, melainkan akan dibawa ke TPA (Tempat Pembuangan Akhir) atau ke landfill untuk selanjutnya ditimbun dengan cara memadatkan sampah. Produksi sampah kertas pada AVU disesuaikan dengan jumlah kebutuhan. Sampah kertas dari perkantoran yang tidak terpakai lagi 
akan dihancurkan menggunakan alat yang disebut dengan paper shredder.

Kertas yang digunakan di AVU dapat dikelompokkan menjadi dua jenis, yaitu kertas ecolabelled dan non ecolabelled (Gambar 6). Kertas ecolabelled merupakan jenis kertas yang ramah lingkungan. Kertas non ecolabelled merupakan jenis kertas yang belum mempunyai label sertifikasi ramah lingkungan. Perhitungan dengan membagi penggunaan kertas dengan ukuran aktivitas (activity measure) telah diperoleh (Gambar 8), didapatkan pada tahun 2018 sebanyak 0,157 kg per guest night. Kertas yang digunakan di AVU ini dapat berupa sedotan kertas maupun bahan bacaan yang dibaca pada setiap kamar.

\section{Produksi Sampah Plastik dan Strategi Minimalisasinya}

Plastik umumnya merupakan bahan yang mempunyai sifat sulit terurai dan membutuhkan waktu cukup lama untuk dihancurkan, plastik dapat terbentuk dari produk polimerisasi sintetik atau semi-sintetik. Polimer sendiri merupakan rantai berulang dari atom yang panjang dan gabungan dari beberapa molekul monomer (Flinn \& Trojan, 1975). Bahan-bahan sintetis yang ada di alam dapat menggantikan minyak dan gas sehingga dapat diperoleh sifat-sifat plastik yang diinginkan dengan cara kopolimerisasi, laminasi, dan ekstruksi (Syarief et al., 1989). Terdapat banyak jenis plastik yang dapat diketahui, salah satunya adalah PolyEthylene Terephthalate (PET). Jenis plastik PET ini juga digunakan pada AVU. Sifat fisik dari PET ini ialah memiliki sifat yang tidak beracun, transparan dan memiliki kekuatan mekanik yang tinggi (Okatama, 2016). Berdasarkan sifat fisik yang dimiliki oleh plastik jenis PET, menandakan bahwa plastik tesebut dapat didaur ulang dengan mudah. Plastik jenis ini juga dapat lunak dan mencair apabila melalui proses pemanasan pada suhu $100^{\circ} \mathrm{C}$.

Menurut Okatama (2016), sifat permeabilitas dari plastik jenis PET tergolong rendah dan dapat diabaikan oleh karbon dioksida serta memiliki kekuatan impak dan kekuatan tarik yang sangat baik. Bahan baku pembuatan plastik umumnya adalah minyak dan gas sebagai sumber alami. Plastik jenis PET ini memiliki ciri warna yang khas, yaitu jernih atau transparan atau tembus pandang. Plastik juga banyak ditemui pada berbagai tempat, seperti di kawasan industri, khususnya industri perhotelan.

Alila Villas Uluwatu sudah mengurangi penggunaan bahan plastik dari tahun 2016 sebelum adanya Peraturan Gubernur Bali Nomor 97 Tahun 2018 Tentang Pembatasan Timbulan Sampah Plastik Sekali Pakai yang ditetapkan dan diundangkan pada tanggal 21 Desember 2018. Menurut Bapak Muliarta pada saat diwawancara, hal ini dilakukan karena pihak hotel sudah menyadari banyaknya permasalahan lingkungan yang disebabkan oleh plastik, baik di darat maupun di laut, padahal plastik yang masih tersisa bisa didaur ulang menjadi produk baru, seperti digunakan paving untuk jalan. Menurut Peraturan BPOM (2019), PET sebaiknya hanya untuk satu kali pakai dan tidak untuk mewadahi pangan dengan suhu lebih dari $60^{\circ} \mathrm{C}$. Plastik jenis PET mempunyai lapisan polimer yang dapat meleleh dan mengandung zat karsinogen yang dapat memicu penyakit kanker.

Berdasarkan data yang didapat pada penelitian ini, Alila Villas Uluwatu pada tahun 2018 tergolong stabil dan efektif dalam strategi pengurangan penggunaan plastik sekali pakai. Dilihat dari data diagram di bawah, dapat direpresentasikan bahwa total jumlah plastik yang digunakan berbanding lurus dengan jumlah plastik yang didaur ulang. Jika terdapat sisa plastik yang dihasilkan oleh AVU, sisa sampah plastik ini akan dibawa ke TPA (Tempat Pembuangan Akhir) atau biasa disebut dengan lokasi landfill. Kegiatan ini juga mendukung program dari Alila Villas Uluwatu yaitu landfill to zero waste untuk mengurangi limbah yang berpotensi berdampak besar bagi lingkungan.

Strategi pengurangan penggunaan plastik pada AVU diwujudkan dalam beberapa produk yang ramah lingkungan, seperti sikat gigi dengan pegangan yang terbuat dari kayu, sedotan kertas serta sedotan bambu. Hal tersebut selain untuk 
mengurangi penggunaan sampah plastik, juga berguna untuk menambah bahan edukasi bagi wisatawan karena sikat gigi dengan pegangan kayu tersebut setelah check out dari hotel bisa dibawa pulang. Selain sikat gigi, sedotan dan produk lotion yang diproduksi AVU sendiri pun dapat diambil jika wisatawan memerlukan dan menyukainya.

Berdasarkan hasil perhitungan dengan membagi penggunaan plastik dengan activity measure (guest night) dapat dilihat bahwa penggunaan plastik pada tahun 2018 sebanyak $0,088 \mathrm{~kg}$ per guest night. Hal ini sesuai dengan jumlah guest night yang berkunjung ke AVU, pada tahun 2018 sebanyak 47.396 guest night. Sampah plastik yang dihasilkan Alila Villas Uluwatu termasuk sangat sedikit, yaitu $0,088 \mathrm{~kg}$ per guest night. Kecilnya produksi sampah plastik ini mengindikasikan kesuksesan usaha-usaha yang sudah ditempuh dari hotel ini dalam meminimalisasi produksi sampah plastiknya. Hal ini dilakukan antara lain melalui kampanye pengurangan sampah plastik, kerjasama dengan stakeholders di dalam pelaksanaan programnya dan memanfaatkan bahan alternatif pengganti bahan plastik.

\section{SIMPULAN}

Pengelolaan sampah di Alila Villas Uluwatu bekerja sama dengan perusahaan lokal Tambyak Lestari. Produksi sampah pada ketiga jenis sampah yaitu kaca, kertas dan plastik pada tahun 2018 sebanyak 0,402 kg per guest night. Ketiga jenis sampah tersebut pada tahun 2018 digunakan sebanyak 19.069,9 kg. Usaha-usaha untuk mengurangi produksi sampah yang sudah dilakukan AVU yaitu dengan menggunakan bahan ramah lingkungan dengan tidak mengurangi fungsi bahan tersebut dalam upaya mengurangi dampak negatif yang ditimbulkan dari kegiatan perhotelan. Usaha lainnya adalah konsisten dalam implementasi pengurangan produksi sampah yang dirasa kurang efektif untuk dipakai.

\section{UCAPAN TERIMA KASIH}

Penulis mengucapkan terima kasih kepada Tuhan YME. Penulis juga menyampaikan terima kasih kepada orang tua yang telah memberikan dukungan moral dan material, Bapak I Ketut Muliarta serta tim Alila Villas Uluwatu yang telah memberikan ijin untuk melakukan penelitian di dalam kawasan hotel, serta pihak-pihak terkait yang tidak dapat disebutkan satu-persatu.

\section{KEPUSTAKAAN}

Alfionita T, Rahardian. 2019. Calcium Chloride $\left(\mathrm{CaCl}_{2}\right)$ : Characteristics and Molecular Interaction in Solution. Pendidikan Kimia, Universitas Negeri Padang: Padang.

Alila Hotels and Resorts. 2020. "Location". https://www.alilahotels.com/uluwatu\#snaplocations. (Diakses pada tanggal $19 \mathrm{Mei}$ 2021).

Bagiastra IK, Damayanti SLP. 2019. Pengolahan Sampah Basah Dengan Menggunakan Stater di Hotel Lombok Raya. Media Bina Ilmiah 14(1): 1939-1948.

Basuki S. 2006. Metode Penelitian. Wedatama Widya Sastra: Jakarta.

Brian R. 2019. Kajian Literatur Pengaruh Nilai Kesadaran Lingkungan bagi Perilaku Konsumen terhadap Green Hotel Practice. Jurnal Hospitality dan Pariwisata 5(1): 1-85.

Dalem AAGR, Widana IN, Simpen IN, Artawan IN. 2010. Effort Performed by Hotels in Bali in Looking After the Environment. Jurnal Lingkungan Hidup Bumi Lestari. 1(10): 113122

Data Guest Night. 2018. Alila Villas Uluwatu Bali.

Departemen Perindustrian, 1982. Perkembangan Industri Kertas dan Pulp di Indonesia dan Dunia (Bagian A-B). Biro Data dan Analisa: Jakarta.

Flin RA, Trojan PK. 1975. Engineering Materials and Their Aplications. Honh Ton Mifflin Co: Boston.

Hasanah H. 2017. Teknik-Teknik Observasi: Sebuah Alternatif Metode Pengumpulan Data Kualitatif Ilmu-ilmu Sosial. Jurnal atTaqaddum 8(1): 21-46. 
Kementerian Pariwisata Republik Indonesia. 2016. Panduan dan Pedoman Pelaksanaan Green Hotel di Indonesia. Jakarta.

Noel CS. 1998. The Glass and Glazing Handbook. Standards Australia SAAHB125: Australia.

Okatama I. 2016. Analisa Peleburan Limbah Plastik Jenis Polyethylene Terphtalate (PET) Menjadi Biji Plastik Melalui Pengujian Alat Pelebur Plastik. Jurnal Teknik Mesin 5(3): 109-113.

Peraturan Badan Pengawas Obat Dan Makanan Nomor 20 Tahun 2019 Tentang Kemasan Pangan.

Peraturan Gubernur Bali Nomor 97 Tahun 2018 Tentang Pembatasan Timbulan Sampah Plastik Sekali Pakai.

PT. Bukit Uluwatu Villa Tbk. 2020. https://www.buvagroup.com/id/sekilasperseroan/corporate-social-responsibilitytes/ (Diakses pada 11 Juli 2020).

Puteri RM. 2017. Kajian Permasalahan Pengelolaan Sampah dan Dampak Lingkungan di TPA (Tempat Pemrosesan Akhir). Jukung Jurnal Teknik Lingkungan 3(1): 66-74.

Ruiz Molina, Irene GS, Beatriz MV. 2010. Good Environmental Practices for Hospitality and Tourism: The Role of Information and Communication Technologies. Management of Environmental Quality: An International Journal 21(4): 464-476.
Shairullizan N, Nabiha, Siti, Nabsiah. 2013. The Barriers to the Adoption of Environmental Management Practices in the Hotel Industry: A Study of Malaysian Hotels. Business Strategy Series 14(4): 106-117.

Syarief RS, Santausa, Isyana B. 1989. Teknologi Pengemasan Pangan. Laboratorium Rekayasa Proses Pangan Pusat Antar Universitas dan Gizi. Institut Pertanian Bogor: Bogor.

Teng CC, Lu ACC, Huang TZT. 2018. Drivers of Consumers' Behavioral Intention Toward Green Hotels. International Journal of Contemporary Hospitality Management.

Undang-undang No.18 Tahun 2008 tentang Pengelolaan Sampah

Wahyuningsih H. 2020. Studi Perencanaan Pengelolaan Dampak Lingkungan Berkelanjutan pada Bangunan Jenis Cabin Hotel. Jurnal Arsitektur NALARs 19(2): 149156.

Webster K. 2006. Environmental Management in the Hospital Industry: A Guide for Students and Managers. Thomson Learning: London, UK.

\section{Wawancara}

Wawancara langsung dengan Bapak I Ketut Muliarta selaku Environment and General Affair Manager Alila Villas Uluwatu pada tanggal 7 Januari 2020 yang bertempat di Alila Villas Uluwatu. 